\title{
The Psychological Profile of Youth Male Soccer Players in Different Playing Positions
}

\author{
Amira Najah1,2, Riadh Ben Rejeb² \\ ${ }^{1}$ Exercise and Sport Science Department, Aspetar Orthopaedic and Sports Medicine Hospital, Doha, Qatar \\ ${ }^{2}$ Psychology Department, University of Human and Social Sciences, Tunis, Tunisia \\ Email: amiranajah@gmail.com
}

Received 24 May 2015; accepted 18 July 2015; published 21 July 2015

Copyright (C) 2015 by authors and Scientific Research Publishing Inc.

This work is licensed under the Creative Commons Attribution International License (CC BY).

http://creativecommons.org/licenses/by/4.0/

(c) (i) Open Access

\section{Abstract}

The purpose of this study was to investigate selected psychological skills of male youth soccer players in different playing positions. This study examined possible positional differences of 180 male youth Tunisian soccer players between the ages of 15 and 19 years old from different clubs of 1st and 3rd Youth Class divisions. The subjects were divided into three playing positions, namely, forward $(n=60)$, midfield $(n=60)$ and defense $(n=60)$, and compared with regard to twelve psychological skills measured by means of the Ottawa Mental Skills Assessment Tool (OMSAT-3) of Durand Bush et al. (2001). Results yielded significant differences between basic and psychosomatic subscale scores of the players in different playing positions. Forward players consistently outperformed the other positional groups in motivation, confidence and activation. Defense players outperformed the other positional groups in relaxation, while midfield players showed the lowest psychological skill levels. The results of the study provided support for the hypothesis that positional differences in terms of psychological skills existed. More specifically, statistical evidence suggested that youth soccer players could be differentiated as a function of psychological skill and the position that they played on the team.

\section{Keywords}

Psychological Skill, Ottawa Mental Skills Assessment Tool (OMSAT3), Playing Positions, Youth Soccer

\section{Introduction}

Many previous studies have focused on physical training requirements of different game positions. However, physical skills are not sufficient to allow high performances and athletes require specific mental attributes. In 
today's high level soccer performance, being physically gifted is not enough to succeed at the highest level. Achieving excellence in soccer is a complex inquiry that requires accurate combination of motor and mental skills. High levels of stress or low coping skills, whether on or off the field, can cause alterations in cognitive appraisal and focus that can interfere with physical performance via alterations in muscular tension and physical coordination. The influence of mental state on performance is as important as technical and tactical skills. This is why it should benefit from the same importance in training programs (Taylor \& Wilson, 2005).

In Sport Psychology, a mental skill is identified as a competency which regulates thoughts, feelings and behaviors. It is a resource developed "in a specific task or a restricted class of tasks" (Famose \& Durand, 1988). Various skills are required to apply learned tactics and strategies during trainings and competitions and athletes do not always have the tools to use and control their potential (Demontrond et al., 2006). In addition, these skills may be modulated by various variables. One of the important variables that can be linked with mental skills in soccer is the "playing position". Each position has its own mental demands. Few studies examined players of different positions of the same sport and discovered links with mental skills (Cox \& Yoo, 1995). This will seem to be an important area of research, because demands placed upon athletes differ as a function of playing position.

Over the last five decades, the role of applied psychology in soccer has experienced some growth in Western countries. In Arab countries, the awareness of the important role of mental attributes is growing at a slow level (Allawy, 2004; Salmela, 1992). Most of the researches conducted in the Arab countries have traditionally been limited to theoretical psychological concepts or being conducted in the field by physical educators or graduated students interested. When examining the psychology Arab literature, we observed that the majority of the topics published were restricted to "personality" (Arfa, 2004; Ouadghiri, 1988), "anxiety" (Allawy, 2004), "causal attribution" (El Arabi \& Esmail, 1987), the "cause of success" (Baria, Nabli, \& Oubahammou, 2003), "motivation" (Nabli, Baria, \& Oubahammou, 2003a, 2003b) or competitive behavior (Baria, 1987; Baria \& Salmela, 1988; El Arabi \& Esmail, 1987). The typical research model used in these studies compared successful and unsuccessful athletes of different ages and genders.

There is evidence that players in different playing positions tend to have different psychological skill levels. Soccer players in attacking positions were shown to have significantly higher levels of emotional instability in comparison to players in defensive positions. Thelwell et al. (2006) examined the efficacy of a mental intervention program on the technical skills pertinent to soccer midfielders. Results yielded that the mental skills training program, comprising relaxation, imagery and self-talk led to improvement in each of the selected technical task specific to the midfield position. However, recent studies maintain that there is no meaningful difference between position specific play in soccer and various psychological attributes (Jooste, 2014; Kurt et al., 2012). Regardless of the existing findings pertaining to diversity of psychological attributes in each playing position, knowledge about psychological skills within soccer environment is limited. Limited research has been directed toward defining a specific mental profile of professional soccer players (Heyman, 1992; Raglin, et al., 1990). The main cause lies in the difficulty to understand psychological dimensions of an individual player in a group, because various individual and collective mental skills may be intimately linked (Feltz \& Ewing, 1987; Mahoney et al., 1987; Cox \& Liu, 1993). Research findings on this topic from other sporting codes will be outlined. Cox \& Yoo (1995) examined the relationships between selected psychological skills and playing position in American football players. Results showed a significant player position main effect, and a significant interaction between team and player position. Significant differences were found between line and backfield players for anxiety control, concentration, and confidence. Significant differences were also observed between offensive and defensive players for anxiety control. The most consistent observation was that a difference in psychological skill existed between linesmen and backfield players, regardless of team (offense/defense). In rugby, Andrew et al. (2007) found that hookers and half-backs outperformed in seven selected psychological skills compared to locks, wings and fullbacks.

Based on current evidences, it is clear that positional differences do exist with regard to psychological skills among athletes from various sporting codes. The question whether or not such differences exist among soccer players remains. Therefore, the aim of this study is to investigate selected psychological skills of youth soccer players in different playing positions.

\section{Material and Methods}

This study was part of a larger research programme investigating selected psychological skills among athletes 
from various age categories, sports divisions and playing positions. The current study focused on the differences of psychological skills among footballers form various playing positions.

\subsection{Participants}

The sample consisted of male Tunisian youth soccer players $(n=180)$, from different U19 (from 17 and 18 years old) and U17 (from 15 to 16 years old) youth soccer class teams. The ages of the players ranged between 15 and 19 years. Half of the players had been playing soccer in famous clubs with larger budgets and more elaborate facilities and at a very top division (youth class 1). The other half of the players had been playing soccer in clubs with moderate budgets and facilities and at a moderate division (youth class 3). Players were divided into three positional groups based on their primary playing positions during the season 2013-2014; defenders (n $=60)$, midfielders $(n=60)$ and forwarders $(n=60)$.

\subsection{Procedures}

The coaches and managers of the participating teams were informed about the aim of the research project prior to the start of the season and were requested to participate. The testing took place during the start of the season. Players and/or their guardians signed a consent form and were free to withdraw their participation at any stage. They were informed about the nature and purpose of the study, Data would be considered confidentially and strictly used for research purposes only. The subjects completed the Arabic version of OMSAT-3 of Durand Bush et al. (2001). The duration of testing was 30 to 45 minutes.

\subsection{Measures}

The OMSAT-3 included 48 items and 12 mental skill scales grouped under three major mental areas, each consisting of a number of mental skills: foundation skills (confidence, motivation and goal setting), psychosomatic skills (stress reaction, fear control, relaxation and activation) and cognitive skills (focusing, refocusing, imagery, mental practice and competition planification). The athlete's response is given on a 7-point Likert type scale ranging from "Strongly disagree" [1] to "Strongly agree" [7]. The score is seen as a high value when it is 6 or 7, medium or moderate between 3 to 5 and low if it is 1 or 2. Results of the OMSAT demonstrated high levels of internal consistency (alpha levels above 0.78 ), and acceptable levels of test-retest reliability ( $\mathrm{rlevels}$ above 0.63 ). Overall, the OMSAT appears to provide a potentially useful assessment and diagnostic tool for both understanding, and potentially, counselling athletes of different ability levels.

\subsection{Statistical Procedures}

Various statistical parameters were calculated using the software "IBM SPSS Statistics 21". Multivariate analysis of variance (MANOVA) was used in order to determine whether multiple levels of our independent variables on their own or in combination with one another have an effect on the dependent variables. The independent variables are the play positions divided into three modalities; forward, midfielder and defense. Two age groups category are taken into account; Junior A (U19) and Junior B (U17) and two environmental categories are defined; 1st youth class and 3rd youth class. The dependent variables are the mental skills expressed through scores of The Ottawa Mental Assessment Skills Test 4 (OMSAT-3) and subdivided into three subscales; basic skills (goal setting, confidence and motivation), psychosomatic skills (stress reaction, fear control, relaxation and activation) and cognitive skills (focus, refocus, imagery, mental practice and competition planification). Descriptive statistics (mean and standard deviation) were examined. For all statistical analyses, $p \leq 0.05$ was adopted as the significance level and $n s$ corresponded to no significance. Effect size was calculated with Wilks's lambda distribution, to consider significance of results and to report only significant interactions. $d f$, corresponds to degrees of freedom. $F$ Value is the $F$ statistic associated with the given source and $F(d f 1$ and $d f 2) \mathrm{Val}$ $u e$ lists the degrees of freedom used in determining the $F$ statistic. $\eta_{\rho}^{2}$ is the second estimate of effect size. $\eta_{\rho}^{2}$ is very useful in comparing the strength of association between independent and dependent variables that excludes variance from other factors.

\section{Results}

The purpose of this study was to investigate selected psychological skills of youth soccer players in different 
playing positions. More specifically; it aimed to determine the extent to which these factors differentiate between youth class categories and age categories. Tables 1 to 5 report on the comparisons between the different variables (players' positions, team classes and age categories) and psychological skills.

Statistically significant differences were found between the three playing positions in the basic skills (Wilks' Lamda $\left.=0.925, \mathrm{~F}_{2,177}=2.331, p<0.05, \eta_{\rho}^{2}=0.038\right)$ and the psychosomatic skills (Wilks' Lamda $=0.840$, $\left.\mathrm{F}_{2,177}=3.965, p<0.05, \eta_{\rho}^{2}=0.084\right)$ (Table 1). Follow-up tests on each dependent factor, applying Bonferroni adjustment, indicated significant differences in the following factors; confidence $\left(\mathrm{F}_{2,177}=3.455, p<0.05, \eta_{\rho}^{2}=\right.$ $0.038)$, and motivation $\left(\mathrm{F}_{2,177}=4.040, p<0.05, \eta_{\rho}^{2}=0.044\right)$ relaxation $\left(\mathrm{F}_{2,177}=4.764, p<0.05, \eta_{\rho}^{2}=0.051\right)$, and activation $\left(\mathrm{F}_{2,177}=8.326, p<0.05, \eta_{\rho}^{2}=0.086\right)$. Forwarders showed higher mean values on confidence and motivation than defenders and midfielders. There were not significant differences between the three groups in the basic skill goal setting. Defenders showed higher mean values on relaxation than forwarders and midfielders. Forwarders showed high means values on activation than defenders and midfielders. No significant differences were found between the three groups in the psychosomatic skills, stress reaction and fear control. There were not significant differences between the three playing positions in the cognitive skills of the OMSAT (Wilks' Lamda $=0.939, \mathrm{~F}_{2,177}=1.100, n s$ ).

In 1st Youth Class group (Table 2), no significant differences were found between the three playing positions in the basic skills (Wilks' Lamda $=0.932, \mathrm{~F}_{2,87}=1.010, n s$ ), the psychosomatic skills of (Wilks' Lamda $=0.872$, $\mathrm{F}_{2,87}=1.492, n s$ ) and the cognitive skills (Wilks' Lamda $=0.887, \mathrm{~F}_{2,87}=1.030, n s$ ).

In the 3rd Youth Class group (Table 3), significant differences were examined between the three playing positions in the basic skills (Wilks' Lamda $=.785, \mathrm{~F}_{2,87}=3.643, p<0.05, \eta_{\rho}^{2}=0.114$ ) and the psychosomatic skills (Wilks' Lamda $=0.741, \mathrm{~F}_{2,87}=3.393, p<0.05, \eta_{\rho}^{2}=0.139$ ). Follow-up tests on each dependent factor, applying Bonferroni adjustment, indicated significant differences in the following factor; confidence $\left(\mathrm{F}_{2,87}=\right.$ $\left.6.168, p<0.05, \eta_{\rho}^{2}=0.124\right)$ and activation $\left(\mathrm{F}_{2,87}=7.667, p<0.05, \eta_{\rho}^{2}=0.150\right)$. Forwarders of the 3rd Youth Class showed high means values on confidence than midfielders. There were not significant differences between the three groups in the basic skills goal setting and motivation. Forwarders of the 3rd Youth Class showed high means values on activation than midfielders. No significant differences were found between the three groups in the psychosomatic skills stress reaction, fear control and relaxation. There were not significant differences between the three playing positions in the cognitive skills of the OMSAT (Wilks' Lamda $=0.893 \mathrm{~F}_{2,87}=0.968, n s$ ).

In the U19 group (Table 4), significant differences were found between the three playing positions in the ba-

Table 1. Means (M), Standard Deviations (SD) in the subscale of the OMSAT 3 based on athletes' playing positions.

\begin{tabular}{cccc}
\hline $\begin{array}{c}\text { OMSAT-4 } \\
\text { Subscales }\end{array}$ & $\begin{array}{c}\text { Defenders } \\
(\mathrm{n}=60) \\
\mathrm{M} \pm \mathrm{SD}\end{array}$ & $\begin{array}{c}\text { Midfielders } \\
(\mathrm{n}=60)\end{array}$ & $\begin{array}{c}\text { Forwarders } \\
(\mathrm{n}=60) \\
\mathrm{M} \pm \mathrm{SD}\end{array}$ \\
\hline Goal setting & $5.90 \pm 0.83$ & $6.01 \pm 0.58$ & $6.05 \pm 0.96$ \\
Confidence & $5.97 \pm 0.87$ & $5.77 \pm 0.92$ & $6.24 \pm 1.09^{\circ *}$ \\
Motivation & $6.20 \pm 0.81$ & $6.33 \pm 0.54$ & $6.55 \pm 0.66^{\circ *}$ \\
Stress reaction & $4.94 \pm 1.02$ & $4.66 \pm 0.94$ & $4.95 \pm 0.99$ \\
Fear control & $4.17 \pm 1.21$ & $4.14 \pm 1.16$ & $4.23 \pm 1.24$ \\
Relaxation & $5.42 \pm 1.00^{* 0}$ & $4.91 \pm 0.96$ & $4.93 \pm 1.07$ \\
Activation & $5.25 \pm 1.05$ & $5.06 \pm 0.84$ & $5.75 \pm 0.98^{\circ *}$ \\
Focusing & $5.64 \pm 1.03$ & $5.30 \pm 0.77$ & $5.46 \pm 0.97$ \\
Refocusing & $5.05 \pm 1.18$ & $4.87 \pm 0.84$ & $5.21 \pm 1.07$ \\
Imagery & $5.36 \pm 1.15$ & $5.37 \pm 1.25$ & $5.55 \pm 1.37$ \\
Mental practice & $5.32 \pm 1.16$ & $5.25 \pm 1.32$ & $5.52 \pm 1.52$ \\
Competition planification & $5.80 \pm 1.07$ & $5.86 \pm 0.87$ & $5.99 \pm 0.92$ \\
\hline
\end{tabular}

'Significantly higher than defenders; *Significantly higher that midfielders; ${ }^{\circ}$ Significantly higher than forwarders. 
Table 2. Means (M), Standard Deviations (SD) in the subscale of the OMSAT 3 based on Youth Class 1 athletes' playing positions.

\begin{tabular}{cccc}
\hline $\begin{array}{c}\text { OMSAT } \\
\text { Subscales }\end{array}$ & $\begin{array}{c}\text { Defenders } \\
(\mathrm{n}=30)\end{array}$ & $\begin{array}{c}\text { Midfielders } \\
\mathrm{M} \pm \mathrm{SD}=30)\end{array}$ & $\begin{array}{c}\text { Forwarders } \\
\mathrm{M} \pm \mathrm{SD}=30) \\
\mathrm{M} \pm \mathrm{SD}\end{array}$ \\
\hline Goal-setting & $5.90 \pm 0.80$ & $5.93 \pm 0.69$ & $6.23 \pm 0.71$ \\
Confidence & $6.01 \pm 0.84$ & $5.87 \pm 0.97$ & $6.05 \pm 1.36$ \\
Motivation & $6.30 \pm 0.82$ & $6.27 \pm 0.56$ & $6.58 \pm 0.64$ \\
Stress reaction & $4.75 \pm 1.07$ & $4.63 \pm 0.85$ & $4.70 \pm 1.00$ \\
Fear control & $4.13 \pm 1.14$ & $3.91 \pm 1.27$ & $4.33 \pm 1.37$ \\
Relaxation & $5.56 \pm 0.93$ & $5.12 \pm 1.01$ & $5.08 \pm 1.09$ \\
Activation & $5.28 \pm 1.10$ & $5.05 \pm 0.83$ & $5.58 \pm 1.07$ \\
Focusing & $5.65 \pm 1.16$ & $5.30 \pm 0.81$ & $5.18 \pm 1.02$ \\
Refocusing & $4.96 \pm 1.16$ & $4.77 \pm 0.75$ & $4.95 \pm 1.04$ \\
Imagery & $5.28 \pm 1.19$ & $5.58 \pm 1.12$ & $5.55 \pm 1.50$ \\
Mental practice & $5.17 \pm 1.32$ & $5.52 \pm 1.21$ & $5.40 \pm 1.65$ \\
\hline
\end{tabular}

Significantly higher than defenders; "Significantly higher that midfielders; 'Significantly higher than forwarders.

Table 3. Means (M), Standard Deviations (SD) in the subscale of the OMSAT 3 based on Youth Class 3 athletes' playing positions.

\begin{tabular}{|c|c|c|c|}
\hline $\begin{array}{l}\text { OMSAT } \\
\text { Subscales }\end{array}$ & $\begin{array}{c}\text { Defenders } \\
(n=30) \\
M \pm S D\end{array}$ & $\begin{array}{l}\text { Midfielders } \\
\qquad \begin{array}{l}(\mathrm{n}=30) \\
\mathrm{M} \pm \mathrm{SD}\end{array}\end{array}$ & $\begin{array}{l}\text { Forwarders } \\
\qquad \begin{array}{l}(\mathrm{n}=30) \\
\mathrm{M} \pm \mathrm{SD}\end{array}\end{array}$ \\
\hline Goal-setting & $5.90 \pm 0.87$ & $6.10 \pm 0.45$ & $5.88 \pm 1.15$ \\
\hline Confidence & $5.94 \pm 0.91$ & $5.68 \pm 0.88$ & $6.43 \pm 0.70^{*}$ \\
\hline Motivation & $6.11 \pm 0.80$ & $6.38 \pm 0.52$ & $6.53 \pm 0.69$ \\
\hline Stress -reaction & $5.13 \pm 0.94$ & $4.69 \pm 1.03$ & $5.20 \pm 0.93$ \\
\hline Fear-control & $4.21 \pm 1.30$ & $4.37 \pm 1.02$ & $4.14 \pm 1.12$ \\
\hline Relaxation & $5.28 \pm 1.06$ & $4.71 \pm 0.88$ & $4.77 \pm 1.04$ \\
\hline Activation & $5.23 \pm 1.01$ & $5.08 \pm 0.86$ & $5.92 \pm 0.75^{*}$ \\
\hline Focusing & $5.64 \pm 0.92$ & $5.30 \pm 0.75$ & $5.74 \pm 0.85$ \\
\hline Refocusing & $5.13 \pm 1.21$ & $4.98 \pm 0.93$ & $5.46 \pm 1.07$ \\
\hline Imagery & $5.43 \pm 1.14$ & $5.16 \pm 1.35$ & $5.56 \pm 1.25$ \\
\hline Mental-practice & $5.46 \pm 0.97$ & $4.98 \pm 1.39$ & $5.65 \pm 1.40$ \\
\hline Competition-planification & $5.89 \pm 0.99$ & $5.84 \pm 0.96$ & $5.99 \pm 0.76$ \\
\hline
\end{tabular}

'Significantly higher than defenders; "Significantly higher that midfielders; 'Significantly higher than forwarders.

sic skills (Wilks' Lamda $=0.814, \mathrm{~F}_{2,88}=3.105, \mathrm{p}<0.05, \eta_{\rho}^{2}=0.098$ ) and the psychosomatic skills (Wilks' Lam$\left.\mathrm{da}=0.713 \mathrm{~F}_{2,88}=3.908, p<0.05, \eta_{\rho}^{2}=0.155\right)$. Follow-up tests on each dependent factors, applying Bonferroni adjustment, indicated significant differences in the following factor; confidence $\left(\mathrm{F}_{2,88}=6.795, p<0.05, \eta_{\rho}^{2}=\right.$ $0.134)$, motivation $\left(\mathrm{F}_{2,88}=5.097, p<0.05, \eta_{\rho}^{2}=0.104\right)$ and activation $\left(\mathrm{F}_{2,88}=9.417, p<0.05, \eta_{\rho}^{2}=0.176\right)$. U19 
Table 4. Means (M), Standard Deviations (SD) in the subscale of the OMSAT 3 based on U19 athletes' playing positions.

\begin{tabular}{cccc}
\hline $\begin{array}{c}\text { OMSAT } \\
\text { Subscales }\end{array}$ & $\begin{array}{c}\text { Defenders } \\
(\mathrm{n}=30) \\
\mathrm{M} \pm \mathrm{SD}\end{array}$ & $\begin{array}{c}\text { Midfielders } \\
(\mathrm{n}=30) \\
\mathrm{M} \pm \mathrm{SD}\end{array}$ & $\begin{array}{c}\text { Forwarders } \\
(\mathrm{n}=30) \\
\mathrm{M} \pm \mathrm{SD}\end{array}$ \\
\hline Goal-setting & $6.06 \pm 0.92$ & $6.13 \pm 0.48$ & $6.08 \pm 0.80$ \\
Confidence & $6.10 \pm 0.92$ & $5.93 \pm 0.76$ & $6.63 \pm 0.57^{\circ *}$ \\
Motivation & $6.25 \pm 0.84$ & $6.32 \pm 0.51$ & $6.74 \pm 0.67^{\circ *}$ \\
Stress -reaction & $5.17 \pm 0.92$ & $4.93 \pm 0.74$ & $4.97 \pm 1.14$ \\
Fear-control & $4.20 \pm 1.11$ & $4.18 \pm 1.22$ & $4.54 \pm 1.35$ \\
Relaxation & $5.54 \pm 1.04$ & $5.25 \pm 0.99$ & $4.97 \pm 1.00$ \\
Activation & $5.47 \pm 0.99$ & $5.19 \pm 0.87$ & $6.14 \pm 0.72^{\circ *}$ \\
Focusing & $5.97 \pm 0.94$ & $5.52 \pm 0.65$ & $5.69 \pm 0.88$ \\
Refocusing & $5.08 \pm 1.17$ & $4.84 \pm 0.69$ & $5.50 \pm 0.87$ \\
Imagery & $5.49 \pm 1.02$ & $5.40 \pm 1.10$ & $5.76 \pm 1.37$ \\
Mental-practice & $5.44 \pm 0.90$ & $5.30 \pm 1.13$ & $5.79 \pm 1.54$ \\
\hline
\end{tabular}

Significantly higher than defenders; "Significantly higher that midfielders; 'Significantly higher than forwarders.

Forwarders showed high means values on confidence and motivation than defenders and midfielders. There were not significant differences between the three groups in the basic skill goal setting. U19 Forwarders showed high means values on activation than defenders and midfielders. There were not significant differences between the three groups in the psychosomatic skills stress reaction, fear control and relaxation. No significant differences were observed between the three playing positions in the cognitive skills of the OMSAT-3 (Wilks' Lamda $\left.=0.868 \mathrm{~F}_{2,87}=1.233, n s\right)$.

In the U17 group, no significant differences between the three playing positions in the basic skills (Wilks' Lamda $=0.953 \mathrm{~F}_{2,86}=0.680, n s$ ), the psychosomatic skills of the OMSAT (Wilks' Lamda $=0.843 \mathrm{~F}_{2,86}=1.852$, $n s$ ) and the cognitive skills (Wilks' Lamda $=0.944 \mathrm{~F}_{2,86}=0.482, n s$ ) were observed (Table 5).

\section{Discussion}

The purpose of the study was to investigate selected psychological skills of youth soccer players in different playing positions. The most consistent observation of this investigation was difference in psychological skill exists between forwarders and defenders regardless of teams' age category or Youth class. The results show that compared to the other playing positions, the forwarders exhibited the highest values, when compared to the defenders and midfielders, in three of the 12 tested mental skill subscales (confidence, motivation and activation). The defenders, compared to the other playing positions scored the highest values in one of the 12 mental skill subscales (relaxation). These findings were consistent with other investigations (Andrew et al., 2007; Eloff et al., 2011).

Forwarders and defenders were more distinguished, in terms of variables related to the degree of excitement; "activation" and "relaxation". The current research supported the idea that at the psychosomatic level, emotional regulation is the basis of the capabilities required to perform motor tasks and to obtain optimum performance. This explains the close relationship between nature of the task and degree of excitement.

The main purpose of forwarders' actions is to keep the ball, disrupt the opponent, accelerate towards the goal and find the perfect time to score. Although the total distance depending on the game station and the game system used is different. Forwarders typically exhibit superior data sprints and intense races that other players. Excessive motor energy and explosion proof are required for the high level of "activation" (Bradley et al., 2010). Defenders' motor tasks are totally different. Primarily, the major defensive action is to protect the goal. Defend- 
Table 5. Means (M), Standard Deviations (SD) in the subscale of the OMSAT 3 based on U17 Athletes' Playing positions.

\begin{tabular}{cccc}
\hline OMSAT & $\begin{array}{c}\text { Defenders } \\
(\mathrm{n}=30) \\
\mathrm{M} \pm \mathrm{SD}\end{array}$ & $\begin{array}{c}\text { Midfielders } \\
(\mathrm{n}=30) \\
\mathrm{M} \pm \mathrm{SD}\end{array}$ & $\begin{array}{c}\text { Forwarders } \\
(\mathrm{n}=30) \\
\mathrm{M} \pm \mathrm{SD}\end{array}$ \\
\hline Goal-setting & $5.74 \pm 0.69$ & $5.90 \pm 0.65$ & $6.03 \pm 1.00$ \\
Confidence & $5.83 \pm 0.80$ & $5.62 \pm 1.06$ & $5.85 \pm 1.33$ \\
Motivation & $6.16 \pm 0.97$ & $6.34 \pm 0.57$ & $6.37 \pm 0.76$ \\
Stress -reaction & $4.69 \pm 1.07$ & $4.39 \pm 1.05$ & $4.92 \pm 0.84$ \\
Fear-control & $4.13 \pm 1.34$ & $4.10 \pm 1.13$ & $3.93 \pm 1.07$ \\
Relaxation & $5.28 \pm 0.96$ & $4.58 \pm 0.82$ & $4.88 \pm 1.15$ \\
Activation & $5.01 \pm 1.07$ & $4.93 \pm 0.80$ & $5.35 \pm 0.96$ \\
Focusing & $5.48 \pm 1.12$ & $5.08 \pm 0.84$ & $5.22 \pm 1.02$ \\
Refocusing & $5.01 \pm 1.21$ & $4.91 \pm 0.98$ & $4.91 \pm 1.19$ \\
Imagery & $5.21 \pm 1.28$ & $5.34 \pm 1.40$ & $5.34 \pm 1.36$ \\
Mental-practice & $5.18 \pm 1.38$ & $5.19 \pm 1.50$ & $5.25 \pm 1.48$ \\
\hline
\end{tabular}

Significantly higher than defenders; "Significantly higher that midfielders; ${ }^{\circ}$ Significantly higher than forwarders.

ers must take the ball and prevent the opponent from advancing. A good quality of emotional and stress management is required to ensure better anticipation of the ball, which explains the degree of awakening (wakefulness relaxation) (Vealey, 2007). Similarly, Burton and Raedeke (2008), reported that relaxation reduces unwanted muscular tension, extreme activation related to the sympathetic nervous system and calms the mind by putting it in relaxed productivity. This optimizes performance, reduces stress and improves self-confidence (Singh et al., 2014).

The inverted U-theory explains perfectly our results. The theory says that the optimum position of functioning regulated by the continuum of excitation depends on the difficulty of the task. Oxendine (1970) adopted this framework and applied three proposals: 1) A slightly higher degree of activation average is required for normal or subnormal level of operation, 2) A high degree of activation is required for physical activities requiring speed, endurance, strength and exclusivity (skills required for the forwarder position), and finally 3 ) A highly high degree of activation is destructive to the complex operation requiring coordination of movements, concentration and balance (skills required for the defender position) (Oxendine, 1970).

Forwarders were also distinguished in terms of confidence and motivation. The particularity of their position and the importance paramount of their role in victory, may explain the intentional self-knowledge that enable them to have physical and psychological attributes appropriate to their duties as they are the primary cause for victory. The main responsibility of these players is to score goals, which may contribute to the high commitment levels observed among subjects in this position. The simultaneous high values of confidence and motivation can be explained by the relational continuum existing between the two basic energies. Confidence levels are intimately associated with an increase in effort and motivation, enabling perceptual effectiveness of situations (Hanton et al., 2002). This approval supports the theoretical contribution of the effectiveness of the treatment (Eysenck \& Calvo, 1992) which posted the idea that a high level of confidence promotes motivation, increases focus level and prevents the rise of cognitive anxiety related to compromising performance. Conversely, Bandura (1977) believed that engaging in a specific task improves self-confidence to achieve the task itself. It is plausible that emotional engagement in effective motor process or mental control can improve the perception of the ability to control the activity itself (Hanton et al., 2002).

The absence of statically significant differences in the cognitive subscales among the players in different playing positions might be attributed to the fact that players acquire same multi-cognitive skills related to the different positional demands of the game. 


\section{Conclusion}

The results of this investigation provided support for the hypothesis that positional differences in terms of psychological skills existed. More specifically, evidence suggested that athletes in youth Tunisian soccer could be differentiated as a function of psychological skill and the position that they played on the team. Certain limitations of this study should be kept in mind when ensuing further research. The results of this study were based upon youth soccer players' population consisting of 180 participants. The grouping of the participants into three playing positions (forward, midfield and defense) should be taken into consideration. Caution should therefore be applied when generalizing these results to other soccer playing populations. Future studies should be more specific in terms of playing positions and considering other particular positions. Future research among soccer players should also investigate their perceptions of psychological skill usage for the purpose of self-development in soccer, as well as the effect of mental skills interventions on team performance.

\section{References}

Allawy, H. M. (2004). The Development of Sport Psychology in Egypt. In A. Baria, \& H. Nabli (Eds.), Introduction of Sport Psychology in Africa (pp. 250-255). Marrakech: 1st International Congress of Sport Psychology.

Andrew, M., Grobbelaar, H. W., \& Potgieter, J. C. (2007). Sport Psychological Skill Levels and Related Psychological Factors That Distinguish between Rugby Union Players of Different Participation Levels. South African Journal for Research in Sport, Physical Education and Recreation, 29, 1-14. http://dx.doi.org/10.4314/sajrs.v29i1.25951

Arfa, Y. (2004). Les traits de personnalité comme déterminants des marges de développement des capacités physiques chez les joueurs de handball. In A. Baria, \& H. Nabli (Eds.), Introduction of Sport Psychology in Africa (pp. 69-81). Marrakech: 1st International Congress of Sport Psychology.

Bandura, A. (1977). Self-Efficacy: Toward a Unifying Theory of Behavioral Change. Psychological Review, 84, $191-215$. http://dx.doi.org/10.1037/0033-295X.84.2.191

Baria, A. (1987). Les comportements individuels et interpersonnels pre et postperformance des gymnastes arabes. Unpublished Master Theses, Montréal: University of Montréal.

Baria, A., \& Salmela, J. H. (1988). Competitive Behaviors of Arabic and Olympic Gymnasts. International Journal of Sport Psychology, 3, 171-183.

Baria, A., Nabli, H., \& Oubahammou, L. (2003). Perceptions about the Causes of Sport Success among Moroccan Athletes and Coaches. In R. Stelter (Ed.), New Approaches to Exercise and Sport Psychology: Theory, Methods and Applications. Copenhagen: XIth European Congress of Sport Psychology.

Bradley, P. S., Di Mascio, M., Peart, D., Olsen, P., \& Sheldon, B. (2010). High-Intensity Profiles of Elite Soccer Players at Different Performance Level. Journal of Strength Conditioning Research, 24, 2343-2351. http://dx.doi.org/10.1519/JSC.0b013e3181aeb1b3

Cox, R. H., \& Liu, Z. (1993). Psychological Skills: A Cross-Cultural Investigation. International Journal of Sport Psychology, 24, 326-340.

Cox, R. H., \& Yoo, H. S. (1995). Playing Positions and Psychological Skill in American Football. Journal of Sport Behaviour, 18, 183-194.

Demontrond, P., Fournier, J., \& Vaire-Douret, L. (2006). Optimal Psychological States in French Sport Settings: Flow in Sports. In J. Mohan, \& M. Sehgal (Eds.), Health Psychology: Recent Perspectives (pp. 125-129). New Delhi: Abijheet Publications.

El Arabi, M., \& Esmail, M. (1987). Competitive Behaviors of Egyptian Gymnasts. In J. H. Salmela, B. Petiot, \& T. B. Hoshisaki (Eds.), Psychological Nurturing and Guidance of Gymnastic Talent (pp. 149-162). Montréal: Sport Psyche.

Eloff, M., Monyeki, M. A., \& Grobbelaar, H. W. (2011). A Survey of Mental Skills Training amongst South African Field Hockey Players at Tertiary Institutions. African Journal for Physical, Health, Education, Recreation and Dance, 17, 1-16.

Eysenck, M. W., \& Calvo, M. G. (1992). Anxiety and Performance: The Processing Efficiency Theory. Cognition and Emotion, 6, 409-434. http://dx.doi.org/10.1080/02699939208409696

Famose, J. P., \& Durand, M. (1988). Aptitudes et acquisition des habiletés motrices. Aptitudes et performance motrice. Paris: Editions revue EPS.

Feltz, D. L., \& Ewing, M. E. (1987). Psychological Characteristics of Elite Young Athletes. Medicine and Science in Sports and Exercise, 19, 98-105. http://dx.doi.org/10.1249/00005768-198710001-00002

Hanton, S., \& Connaughton, D. (2002) Perceived Control of Anxiety and Its Relationship to Self-Confidence and Performance. Research Quarterly for Exercise and Sport, 73, 87-97. http://dx.doi.org/10.1080/02701367.2002.10608995

Heyman, S. (1992). Comparisons of Successful and Unsuccessful Competitors: A Reconsideration of Methodological Ques- 
tions and Data. Journal of Sport Psychology, 4, 295-300.

Jooste, J., Steyn, B. J. M., \& Vandenberg, L. (2014). Psychological Skills, Playing Positions and Performance of African Youth Soccer Teams. South African Journal for Research in Sport, Physical Education and Recreation, 36, 85-100.

Kurt, C., Catikkas, F., Ömurlu, I. K., \& Atalag, O. (2012). Comparison of Loneliness, Trait Anger-Anger Expression Style, Self-Esteem Attributes with Different Playing Position in Soccer. Journal of Physical Education and Sport, 12, 39-43.

Mahoney, M. J., Gabriel, T. J., \& Perkins, T. S. (1987). Psychological Skills and Exceptional Athletic Performance. The Sport Psychologist, 1, 181-199.

Nabli, H., \& Baria, A., \& Oubahammou, L. (2003b). Motivation Profiles Moroccan Athletes. In R. Stelter (Ed.), New Approaches to Exercise and Sport Psychology: Theory, Methods and Applications. XIth European Congress of Sport Psychology, Copenhagen, Denmark.

Nabli, H., Baria, A., \& Oubahammou, L. (2003a). An International and Comparative Study of Motivation Profiles among Scholar Cross-Country Athletes. In R. Stelter (Ed.), New Approaches to Exercise and Sport Psychology: Theory, Methods and Applications. XIth European Congress of Sport Psychology, Copenhagen, Denmark.

Ouadghiri, K. (1988). La personnalité des joueurs marocains de football. Mémoire de fin des études. Institut National des Sports, Rabat, Maroc.

Oxendine, J. B. (1970). Emotional Arousal and Motor Performance. Quest, 1, 23-32. http://dx.doi.org/10.1080/00336297.1970.10519673

Raglin, J. S., Morgan, W. P., \& Luchsinger, A. E. (1990). Mood and Self-Motivation in Successful and Unsuccessful Female Rowers. Medicine and Science in Sports and Exercise, 22, 849-853. http://dx.doi.org/10.1249/00005768-199012000-00018

Salmela, J. H. (1992). The World Sport Psychology Sourcebook. Champaign, IL: Human Kinetics.

Singh, M., \& Singh, J. (2014). Comparison of Mental Skills between Medalist and Non-Medalist Football Players. Scholarly Research Journal for Interdisciplinary Studies, 2, 1283-1291.

Taylor, J., \& Wilson, G. (2005). Applying Sport Psychology: Four Perspectives. Champaign, IL: Human Kinetics.

Thelwell, R. C., Greenlees, I. A., \& Weston, N. J. V. (2006). Using Psychological Skills Training to Develop Soccer Performance. Journal of Applied Sport Psychology, 18, 254-270. http://dx.doi.org/10.1080/10413200600830323

Vealey, S. R. (2007). Mental Skills Training in Sport. In G. Tenenbaum, R. Eklund, \& R. Singer (Eds.), Handbook of Sport Psychology. New Jersey: Wiley. http://dx.doi.org/10.1002/9781118270011.ch13 